\title{
Celso Lafer - Estudos de Direito Público
}

Alberto Venancio Filho ${ }^{I}$

$\mathrm{O}_{\mathrm{d}}^{\mathrm{s}} \mathrm{cos}$

APARECIMENTO dos três volumes de Celso Lafer: Direitos humanos, Direito internacional e Filosofia e teoria geral do direito - reunindo alguns de seus numerosos trabalhos, constitui significativa contribuição aos estudos jurídicos em nosso país.

O subtítulo dos volumes: "Um percursos no Direito no século XXI", espelha bem a trajetória de quarenta anos de magistério na Faculdade de Direito da Universidade de São Paulo.

A principal característica dos volumes é o caráter interdisciplinar dos textos. À matéria de direito se ajuntam os sólidos $\mathrm{co}^{-}$ nhecimentos de ciência política da sociologia e até da literatura. Mas esse caráter interdisciplinar se revela de forma patente na integração dos textos, revelando uma unidade no trato das questões jurídicas.

$\mathrm{Na}$ Introdução ele define a obra como tratando de "temas recorrentes" e "frases temáticas", em expressões que bem definem os volumes.

Do extenso texto dos volumes, todos guardando grande importância e com uma erudição contida, há alguns que podem ser considerados mais relevantes.

Oriundo de uma ilustre família judaica, ao ingressar nas Arcadas do Largo de São Francisco, iria encontrar um ambiente intelectual próprio à formação da mentalidade, com a presença de dois grandes professores que deixaram marcas profundas no autor. Coincidentemente no primeiro ano no ensino da Introdução à Ciência do Direito, professor Goffredo Silva Telles, e outro, no último ano no ensino de Filosofia do Direito, professor Miguel Reale.

Do primeiro diria que "suas aulas combinaram uma eloquência desataviada provida do sal da emoção. Tinham a limpidez e a beleza da elaboração destilado do seu pensamento, permeado pela constante preocupação com a conduta ética". Do outro diria que "conseguia amalgamar a serenidade do magistério ao ardor da palavra jovem, inspirada pela ação de nossa Faculdade".

Já com essa sólida base cultural, achou ainda insuficiente essa postura e foi realizar estudos no exterior, nos Estados Unidos. Não preferiu a sofisticação das universidades da "Ivy League" da costa leste, mas preferiu uma universidade tipicamente americana, a Universidade de Cornell, onde teve três grandes mestres: Herbert Briggs, notável internacionalista, o escritor mexicano Octavio Paz e Hannah Arendt.

As aulas de Hannah Arendt, a notável pensadora haurida na melhor tradição europeia, influenciaram Celso Lafer que se tornou o vulgarizador de seu pensamento entre nós, traduzindo e prefaciando seus livros e com os estudos que produziam outro volume.

Ao ingressar na atividade profissional, a Celso Lafer se ofereciam três caminhos: a prática do direito com Alcides Jorge Costa, com quem estagiara no tempo de estudante; o ingresso nas atividades de direção das empresas familiares ou a retomada dos estudos literários que começou com Antonio Candido. 
O percurso acolhido foi o magistério jurídico com o interesse pela doutrina, com os estudos do direito internacional sobre a orientação do professor Vicente Marotta Rangel, de que dá conta o volume 2, Direito internacional. Tratava-se de um ramo de direito novo - o Direito internacional econômico - do qual foi pioneiro com a obra $O$ Convênio internacional do café.

No âmbito desta resenha, não seria possível todos os capítulos da obra, mas destacar alguns deles.

No campo dos direitos humanos, estuda a Declaração Universal dos Direitos Humanos de 1948 e seu alcance para a Teoria dos direitos humanos. Examina a evolução histórica e a dimensão inaugural, tendo como um dos marcos o discurso do presidente Roosevelt sobre as quatro liberdades, logo em seguida a inserção dos direitos humanos na Carta da ONU na Conferência de San Francisco.

Examina a Declaração Universal como desdobramento da Carta da ONU, bem como o processo de sua elaboração, e expõe que a Declaração considera a paz como valor e identifica o sentido de um pacifismo ativo. A declaração pode ser considerada no plano universal, acima do alcance das jurisdições nacionais, e aponta que a Declaração é um dos primeiros textos jurídicos que tratam do direito à vida privada e à intimidade. Emanando de uma Resolução da Assembleia Geral da ONU, não tinha a força de uma lei internacional e, portanto, era uma simples recomendação, mas no decorrer dos anos se transformando num instrumento jurídico. À Declaração se junta a Conferência de Viena sobre Direitos Humanos, de 1993, que adotou uma Declaração e um Programa de Ação. São feitos comentários sobre a Declaração, expondo as três modalidades pelas quais se estrutura a afirmação planetária dos direitos humanos: promoção, controle e garantia.

Os estudos de direito internacional se concentram na análise da Organização Mundial do Comércio, aliando o conhecimento do professor com a experiência de representante do Brasil naquela organização internacional, com as vinculações que teve, no exercício de ministro das Relações Exteriores, com aquela organização.

Concentra-se no tema da solução de controvérsia e vai aprimorando o sistema de solução de controvérsia, indicando o papel dos usos e costumes, não apenas a dimensão da lei mercantil do Direito Internacional. Em 1971 Celso Lafer já examinava esse tema pioneiramente, que era considerado um quebra-cabeça jurídico, que tinha como nota específica ser uma “jurisprudência diplomática”, e essa flexibilidade ajustava ao sistema uma dimensão jurídica.

No ambiente dessas cogitações e dando sequência aos estudos de Direito internacional público-econômico, se detém no litígio entre o Brasil e os Estados Unidos sobre café solúvel que teve a característica de uma "jurisprudência diplomática”, pois não obedece ao rigor da aplicação das normas jurídicas.

Em 1995 foi o início do funcionamento da Organização Mundial do Comércio (OMC), sucedendo o Galt e com novos quebra-cabeças, mas com novas peças, num tabuleiro maior pela amplitude das matérias dos assuntos cobertos pela OMC e pela posição de seus membros. Em contraste com o Galt, a solução de controvérsias, uma importância que não tinha no ambiente de Galt, ocorrendo o que chamou o aden- 
samento da juridicidade, com a criação de instrumentos especiais e isso abrindo caminho para o pluralismo jurídico das fontes do direito.

Em outro estudo com tema de teoria geral do direito, é o problema da autodeterminação dos povos à luz do artigo 4 da Constituição brasileira e do parecer da Corte Internacional de Haia sobre a independência de Kosovo. Examina minudentemente o princípio da autodeterminação dos povos na Constituição brasileira e na Carta da ONU, para estudar o Parecer Consultivo da Corte Internacional de Justiça, solicitado pela Assembleia Geral da ONU sobre a independência do governo de Kosovo. Analisa o Parecer Consultivo que concluía não haver proibição à declaração da Independência de Kosovo. Examina o impacto político do Parecer Consultivo e aborda múltiplas questões nele citadas, nos votos individuais que foram proferidos.

Em conclusão, o autor expõe que o alcance do princípio da autodeterminação na sua concepção pós-colonial não tem até agora a clareza jurídica necessária. Nessas condições a margem de apreciação mantém semelhança com o método de modulação que vem sendo empregado pelo Supremo Tribunal Federal.

$\mathrm{O}$ outro tema tratado com originalidade é o papel das audiências públicas no Congresso Nacional no campo da política externa. Analisa o papel das Comissões Permanentes do Congresso Nacional e o poder "realizar audiências públicas com entidades de sociedade civil", inovação da Constituição de 1984. Essas audiências têm o objetivo de dar a essas Comissões informação autônoma distinta daquelas transmitidas pelos canais do Executivo.
A necessidade ou a conveniência de escutar o público antes de uma deliberação pode ser considerada, na sua expressão, uma extensão do princípio jurídico de ouvir a outra parte no processo. $\mathrm{O}$ artigo estuda a evolução do texto constitucional e aponta o exemplo do Supremo Tribunal Federal de recorrer a audiência pública para atuar mais adequada das questões submetidas à sua apreciação.

Em conclusão, as audiências públicas trazem a expertise dos diversos campos de conhecimento para tornar inteligível, com a colaboração com a sociedade civil, uma realidade internacional fragmentada.

No capítulo "OMC presença e persistência" examina a participação do Brasil concorrendo para a consolidação institucional da OMC e de suas funções e aborda a adoção do Acordo de Facilitação do Comércio, mostrando que "a diplomacia do comércio internacional é uma diplomacia de concreto, não equacionável apropriadamente por formulações abstratas. Requer muito mapas de conhecimento e a capacidade de integrá-lo".

O estudo "Apontamentos sobre a internacionalização do direito constitucional brasileiro" parte das interações de movimentos inversos, porém complementares, da internacionalização do Direito Constitucional como da constitucionalização do Direito Internacional.

O Direito Constitucional das Relações Internacionais tem uma vertente clássica que é a da distribuição interna da competência entre os poderes do Estado no que tange à sua ação externa, e outra vertente que diz respeito ao processo de recepção de normas internacionais pelos ordenamentos jurídicos nacionais.

O estudo da questão na Constituição portuguesa e na doutrina jurídica daquele povo, que inspiraram o art. $4^{\circ}$ 
da Constituição de 1988, aponta que o preâmbulo do anteprojeto redigido por Afonso Arinos elaborou um abrangente parágrafo sobre o Brasil na ordem internacional. Em função dessa visão, o anteprojeto contém artigos que deveriam reger as relações internacionais do Brasil. Essa proposta representa uma novidade em relação à tradição constitucional brasileira.

$\mathrm{O}$ art. $4^{\circ}$ é indicativo de abertura ao direito internacional, pois seus princípios basicamente regem a comunidade internacional de acordo com a carta da ONU. O artigo examina os vários artigos da Constituição, pois são expressões da Constituição e não apenas Constituição garantia, mas uma Constituição prospectiva e que na pluralidade de seus princípios não cabe uma "ciência", sobre sua articulação, mas uma prudência na sua ponderação. À luz do art. $4^{\circ}$, é assim o marco normativo da função do presidente da República, assessorado pelo ministro do Exterior, a traduzir os interesses em ações diplomáticas do país.

Na conclusão, considera que os princípios do art. $4^{\circ}$ são princípios da relação internacional e como tal são inerentes à política externa de um país, considerando os interesses da manutenção da identidade nacional e o respeito a manutenção da paz universal.

Solicitado a prefaciar inúmeros livros de advogados, professor ex-alunos, os prefácios não são simples resumos dos textos ou elogios ao autor, mas verdadeiros artigos em que tomando por base o texto do autor, desenvolvem as contribuições originais.

O livro contém perfis autobiográficos de colegas com idêntico percurso intelectual e com recordações comoventes das Arcadas.
Em conclusão, os três volumes de Celso Lafer, tratando com competência e originalidade vários ramos do direito, mas mantendo uma linha de interdisciplinaridade, constituem-se em contribuição significativa aos estudos jurídicos no Brasil.

\section{Referência}

LAFER, C. Direitos humanos: um percurso no direito no século XXI, São Paulo: Atlas, Grupo Gen, 2015. v.1.

LAFER, C. Direito internacional: um percurso no direito no século XXI, São Paulo: Atlas, Grupo Gen, 2015. v.2.

\section{LAFER, C. Filosofia e teoria geral do direi-} to: um percurso no direito no século XXI, São Paulo: Atlas, Grupo Gen, 2015. v.3.

Alberto Venancio Filho é advogado, jurista e historiador, membro da Academia Brasileira de Letras. @-avf@bpbc.com.br

Recebido em 26.7.2016 e aceito 15.8.2016.

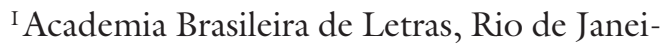
ro/Rio de Janeiro, Brasil. 